УДК 631.436:630:582.866 ВОДНЫЙ РЕЖИМ ЗАРОСЛЕЙ ОБЛЕПИХИ КРУШИНОВИДНОЙ (НIPРОРНAE RHAMNOIDES) ПОБЕРЕЖЬЯ ОЗЕРА ИССЫК-КУЛЬ

\author{
Тотубаева Н.Э., Дуйшебекова С.Б., Кожобаев К.А. \\ Кыргызско-Турецкий университет «Манас», Биикек, е-таil: nurzat.totubaeva@manas.edu.kg
}

\begin{abstract}
Интенсивные изменения состояния окружающей среды требуют разработки достоверных методов оценки его состояния. Наиболее информативным параметром могут служить растения, непосредственно произрастающие в урбосистемах. Произрастая и адаптируясь к различным неблагоприятнымм факторам окружающей среды, они успешно могут быть использованы для оценки качества окружающей среды. Изменение водного режима и ассимиляционной активности растений могут быть использованы для оценки их состояния, а также оценки качества окружающей среды. Как известно, водный режим древесно-кустарниковой растительности зависит от внутренних параметров растений и от факторов окружающей среды. Целью наших исследований было изучение информативности оценки влияния антропогенного фактора на экосистему озера по состоянию водного режима кустарниковых зарослей облепихи крушиновидной, которая произрастает вокруг всей акватории озера, образуя местами непроходимые заросли. Наши исследования показали, что дикорастущие заросли облепихи крушиновидной выработали существенный адаптационный механизм к неблагоприятным факторам среды, что позволяет им расти и плодоносить в условиях повышенного антропогенного воздействия. Но все же прослеживается негативное влияние чрезмерной рекреационной нагрузки на экосистему озера, выражаемое в увеличении интенсивности транспирации, приводящем к увеличению водного дефицита и загниванию плодов облепихи непосредственно на ветках. Все эти факторы могут привести к постепенному их изреживанию и вытеснению из ареала обитания. Для сохранения экосистемы уникального озера Иссык-Куль, при сохранении нынешних объемов рекреационного использования озера и его побережья, необходимо предпринять защитные мероприятия и разработать инженерные меры по его сохранению.
\end{abstract}

Ключевые слова: урбосистема, озеро Иссык-Куль, листья облепихи, интенсивность транспирации, устойчивость растений

\title{
WATER REGIME OF SEA BUCKTHORN (HIPPOPHAE RHAMNOIDES) OF THE ISSYK-KUL LAKE COAST
}

Totubaeva N.E., Duyshebekova S.B., Kozhobaev K.A.

Kyrgyz-Turkish Manas University, Bishkek, e-mail: nurzat.totubaeva@manas.edu.kg

Intense changes in the state of the environment require the development of reliable methods for assessing its condition. The most informative parameter can serve plants directly growing in urban ecosystems. Growing and adapting to various adverse environmental factors, they can be successfully used to assess the quality of the environment. Changes in water regime and assimilative activity of plants can be used to assess their condition, as well as to evaluate the quality of the environment. As is known, the water regime of shrub vegetation depends on internal plant parameters and on environmental factors. The purpose of our researches was to study informative character of anthropogenic factor influence on lake ecosystem by the state of water regime of sea buckthorn bushes. Our researches have shown, that wild-growing bushes of sea buckthorn had developed the essential adaptive mechanism to unfavorable factors of environment that allows them to grow and fructify in the conditions of the raised anthropogenic influence. But still there is a negative impact of excessive recreational load on the ecosystem of the lake, expressed in an increase in the intensity of transpiration, leading to an increase in water deficit and rotting of sea buckthorn fruits directly on the branches. In order to preserve the ecosystem of the unique Lake Issyk-Kul, it is necessary to take protective measures and develop engineering measures for its preservation.

Keywords: urban system, Issyk-Kul lake, sea buckthorn leaves, transpiration intensity, plant resistance

Древесно-кустарниковые растения, растущие в естественных условиях, выполняют огромную средообразующую, водоохранную и множество других функций. Произрастая в различных условиях, они адаптируются к условиям окружающей среды, вырабатывая своеобразные адаптивные механизмы, позволяющие им благополучно существовать. Но изменения, происходящие в природе, зачастую не носят скоростного характера, и поэтому растения успевают выработать адаптивные механизмы [1]. Изменения же, провоцируемые человеком, часто имеют динамичный характер, тем самым интенсивно воздействуя на экосистемы прямым и косвенным путем. Влиянию техногенных факторов на рост и развитие древесно-кустарниковой растительности, произрастающих в урбосистемах, природных парках, лесах, посвящено довольно много исследований [2]. В том числе много работ посвящено изучению морфологического, биохимического, генетического видоизменения различных частей растений при разных типах антропогенного воздействия [3, 4]. Произрастая и адаптируясь к различным неблагоприятным факторам окружающей 
среды, они успешно могут быть использованы для оценки качества окружающей среды. Одним из информативных параметров условий техногенного загрязнения окружающей среды является изменение водного режима и ассимиляционной активности растений $[5,6]$. Как известно, водный режим древесно-кустарниковой растительности зависит от внутренних параметров растений и от факторов окружающей среды [7]. Исследователями установлено, что устойчивость растений к неблагоприятным факторам окружающей среды зависит от содержания и состояния воды в клетках и тканях растений $[8,9]$. Это позволяет дифференцировать их как устойчивые и неустойчивые виды к техногенным изменениям окружающей среды. У устойчивых видов растений различные загрязнения природной среды приводят к увеличению количества связанной и свободной воды и к повышению их водоудерживающей способности. Для оценки степени антропогенного воздействия на прибрежные экосистемы большой интерес вызывают кустарниковые заросли, растущие на побережьях рек, озер и различных водоемов. Они выполняют огромную природоохранную роль, в том числе выполняя роль механического фильтра воды, укрепляя берега и почвы. Зачастую они подвергаются большому антропогенному прессингу: вырубке, перевыпасу скота, ареалы их распространения вычищаются для хозяйственно-бытового использования. С каждым годом растет антропогенное воздействие на уникальную экосистему озера. Растет количество рекреационных учреждений как отвечающих требованиям санитарно-эпидемиологического надзора, так и не соответствующих им. В настоящее время экологическое состояние облепиховых зарослей на побережье озера Иссык-Куля неудовлетворительное. Как известно, самоочищающаяся функция любого природного объекта имеет свой предел, и не всегда известно, когда этот предел будет перейден. С связи в этим экологическое состояние воды и экосистем, обрамляющих озеро Иссык-Куль, является одним из вопросов, вызывающих научный интерес ученых разных специальностей. Нами исследовались возможности оценки влияния антропогенного фактора на экосистему озера по состоянию водного режима кустарниковых зарослей облепихи крушиновидной, которая произрастает вокруг всей акватории озера, образуя местами непроходимые заросли. В связи с этим целью наших исследований являлось изучение водного режима облепиховых зарослей побережья озера Иссык-Куль при различном уровне антропогенного воздействия на экосистему озера - от повышенной до умеренной.

\section{Материалы и методы исследования}

Объектом наших исследований были дикорастущие заросли облепихи крушиновидной побережья озера Иссык-Куль. Отбор проб был произведен в пяти точках (1 - Оттук, 2 -Тамчы, 3 - Чон-Сары-Ой, 4 Чолпон-Ата, 5 - Бостери) (рис. 1). Пункт сравнительно неосвоенного в рекреационном плане участка озера Оттук был взят в качестве контроля.

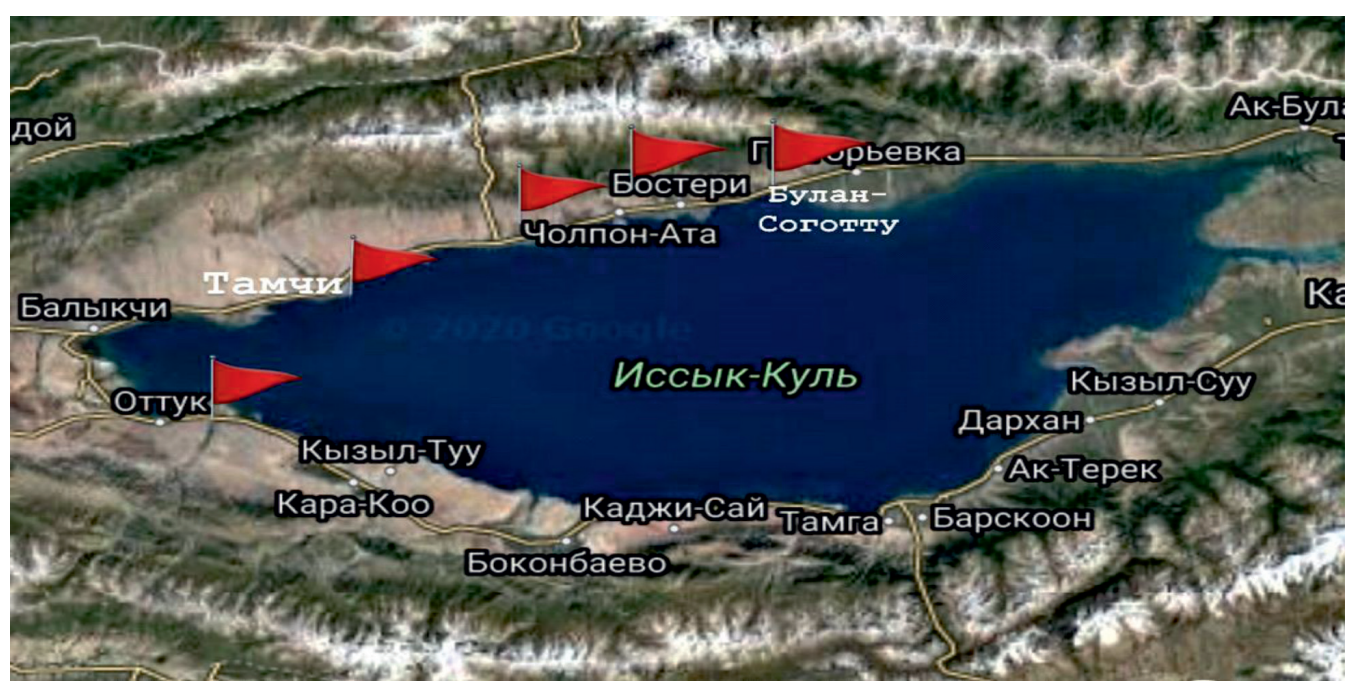

Рис. 1. Пункты отбора образиов 
Показатели водного режима растений

Таблица 1

\begin{tabular}{|c|c|c|}
\hline $\begin{array}{c}\text { Определяемый } \\
\text { параметр }\end{array}$ & Характеристика & Формула \\
\hline $\begin{array}{l}\text { Интенсивность } \\
\text { транспирации }\end{array}$ & $\begin{array}{l}\text { Определена методом быстрых взвешиваний } \\
\text { листьев, пересчетом на } 1 \text { г сырого веса за } \\
1 \text { час. Листья взвешивались дважды: } 1 \text { - вес } \\
\text { до опыта, } 2 \text { - вес через } 3 \text { мин обезвозживания } \\
\text { в комнатных условиях при температуре } 27^{\circ} \mathrm{C} \text {. } \\
\text { По результатам взвешивания рассчитывалась } \\
\text { потеря воды в мг за } 1 \text { час на } 1 \text { г сырой массы } \\
\text { и на единицу площади }(100 \text { см²) листа. Пробы } \\
\text { были отобраны в обеденное время, в августе } \\
2020 \text { г. Повторность опыта 6-8-кратная }\end{array}$ & $\begin{array}{l}\text { ИТ-интенсивность транспирации, } \\
\text { мг/г/час; } \\
P_{1}-\text { начальный вес листа, мг; } \\
P_{2}-\text { вес листа через } 3 \text { мин, мг }\end{array}$ \\
\hline $\begin{array}{c}\text { Содержание воды } \\
\text { в листьях }\end{array}$ & $\begin{array}{l}\text { Листья высушивали в термостате до } \\
\text { постоянного веса при } 105^{\circ} \mathrm{C}\end{array}$ & $\begin{array}{l}C B-\text { содержание воды, } \% ; \\
P_{0}-\text { начальный вес листа, мг; } \\
P_{2}^{0}-\text { абсолютно сухой вес, мг }\end{array}$ \\
\hline Водопотеря & $\begin{array}{l}\text { Расчет водопотери проводили в зависимости } \\
\text { от первоначальной сырой массы листа }\end{array}$ & $\begin{array}{l}B \Pi \text { - водопотеря, \%; } \\
P_{0}-\text { начальный вес листа, мг; } \\
P_{1}^{\prime}-\text { вес через } 1 \text { ч высушивания, мг }\end{array}$ \\
\hline Водный дефицит & $\begin{array}{l}\text { Срезанные листья взвешивали на торсионных } \\
\text { весах и затем погружали их в воду комнатной } \\
\text { температуры, на 2 ч. После того, как листья } \\
\text { насыщались водой, их слегка просушивали } \\
\text { фильтровальной бумагой и повторно } \\
\text { взвешивали }\end{array}$ & $\begin{array}{l}\text { ВД- водный дефицит, \%; } \\
P_{0}-\text { первоначальный вес листа, мг; } \\
P_{1}^{\prime}-\text { вес листа через } 2 \text { ч, мг }\end{array}$ \\
\hline $\begin{array}{l}\text { Засухоустойчи- } \\
\text { вость }\end{array}$ & $\begin{array}{l}\text { Свежесрезанные листья взвешивали на } \\
\text { торсионных весах и обезвоживали в течение } 1 \text { ч } \\
\text { в комнатных условиях при температуре } 27^{\circ} \mathrm{C}\end{array}$ & $\begin{array}{l}\text { КЗУ- коэффициент } \\
\text { засухоустойчивости; } \\
P_{1} \text { - масса листа до высушивания, мг; } \\
P_{2}^{1} \text { - масса листа после } \\
\text { высушивания, мг }\end{array}$ \\
\hline $\begin{array}{c}\text { Жароустойчи- } \\
\text { вость }\end{array}$ & $\begin{array}{l}\text { Определяли высушиванием листьев при } \\
\text { температуре } 40^{\circ} \mathrm{C} \text { в термостате в течение } \\
1 \text { ч, которые были предварительно взвешены } \\
\text { на торсионных весах. После } 1 \text { ч экспозиции } \\
\text { листья повторно взвешивались }\end{array}$ & $\begin{array}{l}\text { КЖУ - коэффициент } \\
\text { жаростойкости; } \\
P_{1}-\text { масса листа до опыта, мг; } \\
P_{2}^{2}-\text { масса листа после опыта, мг }\end{array}$ \\
\hline Солеустойчивость & $\begin{array}{l}\text { Листья предварительно взвешивались на } \\
\text { торсионных весах, далее помещались в чашки } \\
\text { Петри с } 10 \% \text { раствором хлористого натрия на } \\
24 \text { ч. После чего листья вновь взвешивались }\end{array}$ & $\begin{array}{l}\text { КСУ- коэффициент } \\
\text { солеустойчивости; } \\
P_{1} \text { - масса листа до погружения } \\
\text { в раствор, мг; } \\
P_{2} \text { - масса листа после погружения } \\
\text { в раствор, мг } \\
\end{array}$ \\
\hline
\end{tabular}

Пробные площади закладывались в местах ближайшего расположения естественных зарослей облепихи крушиновидной к побережью воды озера Иссык-Куль. Листья были отобраны из средней части хорошо освещенных побегов и побегов, которые расположены на периферии средней части кроны. Свежесобранные листья заворачивали во влажную фланелевую ткань и затем помещали в полиэтиленовый пакет для выравнивания во времени эксперимента [10].

Для изучения водного режима растений определялись следующие показатели, представленные в табл. 1.

\section{Результаты исследования и их обсуждение}

Интенсивность транспирации. Максимальная интенсивность транспирации отмечена в пункте Чолпон-Ата, составив 10600 мг/г/час, а минимальный показатель был в пункте Оттук (табл. 2). Схожие показатели, равные $6850 \pm$, были в пунктах Булан-Соготту и Бостери. Интенсивность транспирации в наиболее часто посещаемом туристами пункте была наиболее высокой, а контрольный вариант Оттук имел наименьший показатель 6000 мг/г/час. Учитывая, что на побережье озера в лет- 
нее время стихийно распологаются летние кафе, вследствие чего вечерний пляж наполняется дымом и гарью, а также кустарники облепихи зачастую используются в качестве урны, возможно, заросли облепихи крушиновидной увеличивают интенсивность транспирации - как защитный механизм к негативным факторам окружающей антропосферы.

Содержание воды в листьях облепихи. Оводненность изучаемых листьев облепихи - один из важных признаков водного режима древостоев [11]. Как показано в табл. 3, содержание воды в пунктах Чолпон-Ата и Тамчы были высокими. Общая средняя величина содержания воды в листьях составила 45,31\%. Наименьший показатель среди исследуемых объектов показали образцы пункта Оттук, содержание воды в котором составило 32,15\%. В пунктах, где уровень антропогенного прессинга повышен, оводненность листьев была высокой $(63,21 \%)$, что, возможно, является адаптационным признаком к повышенной антропогенной нагрузке, но это требует дополнительных исследований и наблюдений.

Водопотеря. Показатели водопотери показали, что пункты, где повышенный уровень транспирации, понижена водоудерживающая способность листьев (табл. 4). Так, в пункте Чолпон-Ата среднее значение водопотери составило 33,53 мг/г/ч, близки к этому показателю данные по пункту Тамчы (29,14 мг/г/час), а наименьший показатель у пункта Оттук, где водопотеря составила $16,45 \mathrm{мг} / г /$ час. Таким образом, в наших исследованиях выявлена зависимость интенсивности транспирации с водоудерживающей способностью листьев, что было также отмечено и другими исследователями [12]. Возможно, повышенная нагрузка на экосистемы озера в пунктах Чолпон-Ата, Тамчы имеет негативное воздействие на дикорастущие заросли облепихи крушиновидной и требует разработки защитных мер по их сохранению.

Интенсивность транспирации опытных образцов

Таблица 2

\begin{tabular}{|c|l|c|c|}
\hline $\begin{array}{c}\text { № } \\
\text { П/п }\end{array}$ & \multicolumn{1}{|l|}{ Пункты отбора } & Среднее значение, $\mathrm{M} \pm \mathrm{m}$, мг/г/час & Коэффициент вариации, $\mathrm{Cv} \%$ \\
\hline 1 & Булан-Соготту & $6800 \pm 14,83$ & 4,38 \\
\hline 2 & Бостери & $6800 \pm 14,83$ & 4,38 \\
\hline 3 & Чолпон-Ата & $10600 \pm 18,96$ & 6,22 \\
\hline 4 & Тамчы & $6850 \pm 12,52$ & 4,11 \\
\hline 5 & Оттук & $6000 \pm 13,45$ & 4,24 \\
\hline
\end{tabular}

Таблица 3

Средние значения содержания воды в изучаемых образцах

\begin{tabular}{|c|l|c|c|}
\hline $\begin{array}{c}\text { № } \\
\Pi / \Pi\end{array}$ & Пункты отбора & Средние значения, $\mathrm{M} \pm \mathrm{m}, \mathrm{мг} / \Gamma /$ час & Коэффициент вариации, $\mathrm{Cv} \%$ \\
\hline 1 & Булан-Соготту & $34,00 \pm 0,18$ & 1,32 \\
\hline 2 & Бостери & $34,00 \pm 0,18$ & 1,32 \\
\hline 3 & Чолпон-Ата & $63,21 \pm 0,32$ & 1,59 \\
\hline 4 & Тамчы & $63,21 \pm 0,32$ & 1,59 \\
\hline 5 & Оттук & $32,15 \pm 0,16$ & 1,25 \\
\hline
\end{tabular}

Таблица 4

Водоудерживающая способность исследованных образцов

\begin{tabular}{|c|l|c|c|}
\hline $\begin{array}{c}\text { № } \\
\Pi / \Pi\end{array}$ & \multicolumn{1}{|l|}{ Пункты отбора } & Средние значения, $\mathrm{M} \pm \mathrm{m}, \mathrm{мг} / \Gamma /$ час & Коэффициент вариации, $\mathrm{Cv} \%$ \\
\hline 1 & Булан-Соготту & $18,23 \pm 0,41$ & 9,58 \\
\hline 2 & Бостери & $19,16 \pm 0,46$ & 10,42 \\
\hline 3 & Чолпон-Ата & $33,53 \pm 0,63$ & 12,16 \\
\hline 4 & Тамчы & $29,14 \pm 0,28$ & 7,86 \\
\hline 5 & Оттук & $16,45 \pm 0,45$ & 6,32 \\
\hline
\end{tabular}


Водопоглощение, или степень водного дефицита, показывает, сколько необходимо воды для восстановления водного дефицита. Наибольший показатель по водному дефициту был в образцах Чолпон-Ата (табл. 5), почти одинаковые результаты были в образцах Тамчы $(15,32)$, Бостери $(15,18)$, Булан-Соготту $(14,05)$, а наименьший показатель водопоглощения был у образца Оттук $(6,68)$. Таким образом, можно считать, что интенсивность транспирации оказывает влияние на степень водного дефицита растения.

Далее, согласно протоколу наших исследований, с целью определения комплексного коэффициента устойчивости, нами были определены коэффициенты засухоустойчивости, жаростойкости и солеустойчивости.

Коэффиииент засухоустойчивости показывает степень выносливости древесного растения к водному дефициту. По литературным данным [13], чем ближе коэффициент засухоустойчивости к 1,0 , тем более устойчивым к засухе видом принято считать растение. Наши исследования показали (табл. 6), что все изучаемые образцы обладали повышенной степенью устойчивости к водному дефициту и обладали повышенной засухоустойчивостью. Возможно, находясь длительное время в условиях повышенного антропогенного воздействия, дикорастущие заросли облепихи крушиновидной выработали повышенную степень засухоустойчивости, что очень важно в аспекте потепления климата и разработки адаптационных механизмов к изменению климата.

Коэффиииент жароустойчивости. Наиболее высокий показатель по жароустойчивости изучаемых образцов был у образцов пункта Булан-Соготту $(0,91)$, а наиболее низким - в пункте Чолпон-Ата $(0,74)$, у остальных вариантов он варьировал в пределах 0,81 (табл. 7). Таким образом, можно судить о незначительном влиянии водного дефицита на жаростойкость образцов. Так в пункте Оттук, где наблюдался наименьший водный дефицит, коэффициент жаростойкости в среднем на $12,3 \%$ выше чем в пунктах Булан-Соготту, Бостери и Тамчы, и на 23,0\% выше, чем в пункте Чолпон-Ата.

Средние показатели степени водного дефицита

Таблица 5

\begin{tabular}{|c|l|c|c|}
\hline $\begin{array}{c}\text { № } \\
\text { П/П }\end{array}$ & \multicolumn{1}{|c|}{ Пункты отбора } & Средние значения, $\mathrm{M} \pm \mathrm{m}, \mathrm{мг} / \mathrm{r} /$ час & Коэффициент вариации, Сv\% \\
\hline 1 & Булан-Соготту & $16,05 \pm 0,41$ & 12,52 \\
\hline 2 & Бостери & $15,18 \pm 0,46$ & 13,18 \\
\hline 3 & Чолпон-Ата & $18,38 \pm 0,63$ & 7,26 \\
\hline 4 & Тамчы & $15,32 \pm 0,28$ & 13,45 \\
\hline 5 & Оттук & $6,68 \pm 0,45$ & 15,61 \\
\hline
\end{tabular}

Коэффициент засухоустойчивости

Таблица 6

\begin{tabular}{|c|l|c|c|}
\hline $\begin{array}{c}\text { № } \\
\text { П/П }\end{array}$ & \multicolumn{1}{|c|}{ Пункты отбора } & Средние значения & Коэффициент вариации, Сv\% \\
\hline 1 & Булан-Соготту & 1,01 & 7,27 \\
\hline 2 & Бостери & 1,04 & 8,14 \\
\hline 3 & Чолпон-Ата & 1,12 & 7,86 \\
\hline 4 & Тамчы & 1,09 & 8,51 \\
\hline 5 & Оттук & 1,1 & 6,45 \\
\hline
\end{tabular}

Коэффициент жароустойчивости

Таблица 7

\begin{tabular}{|c|l|c|c|}
\hline $\begin{array}{c}\text { № } \\
\text { П/П }\end{array}$ & \multicolumn{1}{|c|}{ Пункты отбора } & Средние значения & Коэффициент вариации, Сv\% \\
\hline 1 & Булан-Соготту & 0,91 & 5,78 \\
\hline 2 & Бостери & 0,80 & 3,54 \\
\hline 3 & Чолпон-Ата & 0,74 & 3,68 \\
\hline 4 & Тамчы & 0,81 & 4,59 \\
\hline 5 & Оттук & 0,82 & 4,21 \\
\hline
\end{tabular}


Коэффициент солеустойчивости

\begin{tabular}{|c|l|c|c|}
\hline $\begin{array}{c}\text { № } \\
\text { П/П }\end{array}$ & \multicolumn{1}{|c|}{ Пункты отбора } & Средние значения & Коэффициент вариации, Сv\% \\
\hline 1 & Булан-Соготту & 1,51 & 9,65 \\
\hline 2 & Бостери & 1,47 & 8,52 \\
\hline 3 & Чолпон-Ата & 1,52 & 10,87 \\
\hline 4 & Тамчы & 1,40 & 8,14 \\
\hline 5 & Оттук & 1,80 & 7,49 \\
\hline
\end{tabular}

Показатели комплексного коэффициента устойчивости

Таблица 9

\begin{tabular}{|c|l|c|c|c|c|}
\hline \multirow{2}{*}{$№$} & \multirow{2}{*}{$\begin{array}{c}\text { Пункты } \\
\text { отбора }\end{array}$} & \multicolumn{2}{|c|}{ Коэффициенты } & \multirow{2}{*}{ ККУ } \\
\cline { 3 - 5 } & засухоустойчивости & солеустойчивости & жароустойчивости & \\
\hline 1 & Булан-Соготту & 1,01 & 1,51 & 0,82 & 1,11 \\
\hline 2 & Бостери & 1,04 & 1,47 & 0,80 & 1,10 \\
\hline 3 & Чолпон-Ата & 1,12 & 1,52 & 0,74 & 1,13 \\
\hline 4 & Тамчы & 1,09 & 1,40 & 0,81 & 1,10 \\
\hline 5 & Оттук & 1,1 & 1,80 & 0,91 & 1,27 \\
\hline
\end{tabular}

Коэффициент солеустойчивости. Полученные данные о солеустойчивости изучаемых образцов (табл. 8) показали, что все образцы обладают повышенной солеустойчивостью, наибольшее значение коэффициента $(1,80)$ было в пункте Оттук, наименьший - в пункте Тамчы $(1,40)$, средний показатель был равен 1,54 . Какой-либо зависимости между солеустойчивостью и ранее изученными показателями нами не было обнаружено.

По показателям трех вышеуказанных коэффициентов можно определить комплексный коэффициент устойчивости (ККУ) по отношению к таким экологическим факторам, как солеустойчивость, жаростойкость и засухоустойчивость. ККУ (табл. 9) был наиболее высоким в пункте Оттук $(1,27)$, где сравнительно низкий рекреационный поток туристов, в остальных пунктах этот показатель менялся в сравнительно узких пределах $(1,10-1,13$ - в пункте Чолпон-Ата). Эти данные позволяют предполагать, что дикорастущие заросли облепихи крушиновидной выработали, хотя и незначительно, но адаптационный механизм к неблагоприятным факторам среды, что позволяет им расти и плодоносить в условиях повышенного антропогенного воздействия. Однако визуальные наблюдения за созревшими плодами показали, что большинство созревших плодов в пункте Чолпон-Ата (рис. 2) были загнившими.

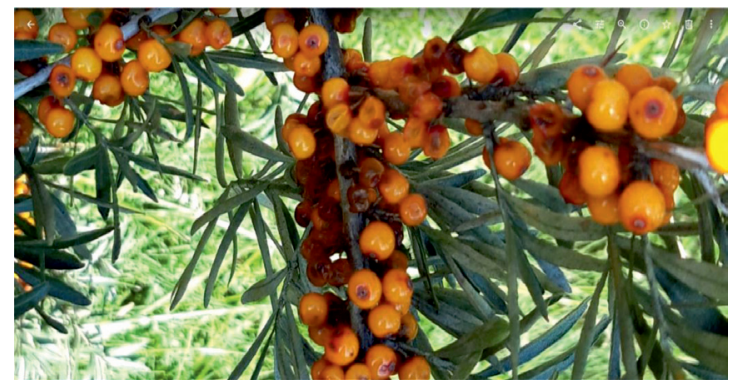

Рис. 2. Созревшие плоды на побережье 2. Чолпон-Ата (на фото Н. Тотубаевой отчетливо видно, что примерно половина плодов загнили уже на ветке)

Таким образом, можно предположить, что повышенное воздействие на экосистему озера Иссык-Куль может иметь негативное последствие, что было показано нами на примере дикорастущих зарослей облепихи крушиновидной, которое выражалось в увеличении интенсивности транспирации, приводящем к увеличению водного дефицита, что, к свою очередь, может привести к ослаблению растений и постепенному их изреживанию и вытеснению из ареала обитания. Как всем известно, в природе изменение и нарушение одной цепочки может привести к постепенным изменениям всей экосистемы, которое, в совокупности с всевозрастающим антропогенным воздействием на прибрежные экосистемы [14], 
может повлечь плачевные последствия для всей экосистемы и качества воды озера Иссык-Куль.

\section{Список литературы}

1. Кулиев А.С. Выращивание дикорастущих форм облепихи крушиновидной (Hippophae rhamnoides L.) из различных регионов Кыргызстана // Universum: химия и биология. 2016. № 9 (27). С. 4-6.

Kuliev A.S. Cultivation of wild forms of sea buckthorn (Hip pophae rhamnoides L.) From different regions of Kyrgyzstan // Universum: khimiya i biologiya. 2016. No. 9 (27). P. $4-6$ (in Russian).

2. Гапонов Д.А. Выявление и оценка геофизическими методами локального техногенного загрязнения геологической среды в местах размещения отходов производства и потребления: автореф. дис. ... канд. геол.-мин. наук. Ростовна-Дону, 2011. 22 с

Gaponov D.A. Identification and assessment by geophysical methods of local technogenic pollution of the geologica environment in the places of disposal of industrial waste and consumption: avtoref. dis. ... kand. geol.-min. nauk. Rostov-naDonu, 2011. 22 p. (in Russian).

3. Гроховатский И.А., Отенов Т.О., Отенова Ф.Т. Облепиха крушиновидная (Hippophoe rhamnoides L.) алтайской вариации в условиях юга Приаралья // Проблемы ботаники Южной Сибири и Монголии: материалы XI Международной научно-практической конференции - Барнаул (Россия), 2012. $57 \mathrm{c}$

Grokhovatskiy I.A., Otenov T.O., Otenova F.T. Sea buckthorn (Hippophoe rhamnoides L.) Altai variation in the south of the Aral Sea region // Problemy botaniki Yuzhnoy Sibiri i Mongolii: materialy XI Mezhdunarodnoy nauchno-prakticheskoy konferentsii - Barnaul (Rossiya), 2012. 57 p. (in Russian).

4. Kalia R., Singh R., Rai M.K., Mishra G.P., Singh S. Dhawan A. Biotechnological interventions in sea buckthorn (Hippophae L.): current status and future prospects. 2011. Trees. 25. P. $559-575$.

5. Вернигора Е.Г., Бурундукова О.Л. Мезоструктура фотосинтетического аппарата елей в стрессовых условиях роста // Тихоок. медиц. журн. 2015. № 2. C. 24-26.

Vernigora E.G., Burundukova O.L. Mesostructure of the photosynthetic apparatus of fir trees under stress growth conditions // Tikhook. medits. zhurn. 2015. No. 2. P. 24-26 (in Russian).

6. Гибадулина И.И. Оценка относительного жизненного состояния древесных насаждений г. Набережные Челны // Городская среда: экологические и социальные аспекты: сборник Всероссийской научно-практической конференции (Ижевск, 19 апреля 2017 г.). Ижевск, 2017. С. 103-108 (а).

Gibadulina I.I. Assessment of the relative vital state of tree plantations in Naberezhnye Chelny // Gorodskaya sreda: ekologicheskiye i sotsial'nyye aspekty: sbornik Vserossiys- koy nauchno-prakticheskoy konferentsii (Izhevsk, 19 aprelya 2017 g.). Izhevsk, 2017. Р. 103-108 (a). (in Russian).

7. Петрова В.И. Трансформация водного режима территории в связи со строительством линейных объектов на примере Кондинского района Ханты-Мансийского автономного округа - Югры: Тюмень, 2017. С. 71-77.

Petrova V.I. Transformation of the water regime of the territory in connection with the construction of linear objects on the example of the Kondinsky district of the Khanty-Mansiysk Autonomous Okrug - Ugra: Tyumen, 2017. P. 71-77 (in Russian).

8. Li X., Sun K., Li F.Y. Variation in leaf nitrogen and phosphorus stoichiometry in the nitrogen-fixing Chinese seabuckthorn (Hippophae rhamnoides L. subsp. sinensis Rousi) across northern China.Ecological research. 2014. Vol. 29. № 4. P. 723-731.

9. Титов А.Ф., Таланова В.В., Казнина Н.М. Физиологические основы устойчивости растений к тяжелым металлам: учебное пособие. Петрозаводск: КарНЦ РАН, 2011. $77 \mathrm{c}$.

Titov A.F., Talanova V.V., Kaznina N.M. Physiological foundations of plant resistance to heavy metals: uchebnoye posobiye. Petrozavodsk: KarNTS RAN, 2011. 77 p. (in Russian).

10. Кулиев А.С. Значение листовых пластинок и таксационные показатели облепихи в естественных популяциях Кыргызстана // Universum: химия и биология. 2017. № 2 (32). C. 14-19.

Kuliev A.S. The value of leaf blades and taxation indicators of sea buckthorn in natural populations of Kyrgyzstan // Universum: khimiya i biologiya. 2017. No. 2 (32). P. 14-19 (in Russian).

11. Yang F.S., Cao M.M., Li H.E., Wang X.H., Bi C.F. Ecological restoration and soil improvement performance of the seabuckthorn flexible dam in the Pisha Sandstone area of Northwestern China, Solid Earth Discuss. 2014. Vol. 6 (2). P. 2803-2842.

12. Ахматов М.К. Дневной расход воды на транспирацию целым древесным растением // Universum: химия и биология. 2016. № 8. С. 26.

Akhmatov M.K. Daily water consumption for transpiration by a whole woody plant // Universum: khimiya i biologiya. 2016. No. 8. P. 26. (in Russian).

13. Алексеенко И.В. Оценка засухоустойчивости малины ремонтантной по некоторым показателям водного обмена в условиях Брянской области // Садоводство и виноградарство. 2019. № 5. С. 23-27.

Alekseenko I.V. Assessment of drought resistance of remontant raspberries by some indicators of water exchange in the conditions of the Bryansk region // Sadovodstvo i vinogradarstvo. 2019. No. 5. P. 23-27 (in Russian).

14. Gioria Margherita, Colette O’Flynn, Bruce A. Osborne. «A Review of the Impacts of Major Terrestrial Invasive Alien Plants in Ireland.» Biology and Environment: Proceedings of the Royal Irish Academy 118B. 2018. No. 3. P. 157-79. 